\title{
Inappropriate medication use among the elderly: a systematic review of administrative databases
}

\author{
Lusiele Guaraldo ${ }^{1,2^{*}}$, Fabíola G Cano ${ }^{1,3}$, Glauciene S Damasceno ${ }^{1}$ and Suely Rozenfeld ${ }^{1}$
}

\begin{abstract}
Background: Inappropriate medication use (IMU) by elderly people is a public health problem associated with adverse effects on health. There are a number of methods for identifying IMU, some involving clinical judgment and others, consensually generated lists of drugs to be avoided. This review aims to describe studies that used information from insurance company and social security administrative databases to assess IMU among community-dwelling elderly and to present the risk factors most often associated with IMU.
\end{abstract}

Methods: The paper search was conducted in Medline and Embase, using descriptors combined with free terms in the title or abstract. The limits applied were: publication date from January 1990 to June 2010, species (human) and publication type (excluding editorials, letters and reviews). Excluded were: case studies; studies in hospitals, nursing homes, or hospital emergency departments; studies of specific drugs or groups of drugs; studies exclusively of subgroups of ill, frail elderly or rural populations. Additional studies were identified from reference lists. Data were selected and extracted after independent reading by two of the authors, with disagreements resolved by a third author. The primary outcome assessed was prevalence of IMU, defined as the proportion of elderly who received at least one inappropriate medication.

Results: Of the 628 studies, 19 met the inclusion criteria, 78.9\% of them conducted in the USA. All papers included used explicit criteria of inappropriateness, most commonly Beers criteria (73.7\%) in their three versions (1991, 1997 and 2002). Other methods used included Zhan, which is derived from on Beers criteria and was applied in 21\% of the papers selected. The study found that prevalence of IMU ranged from $11.5 \%$ to $62.5 \%$. Only $68.4 \%$ of the studies included examined inappropriate use-related factors, the most important being female sex, advanced age and larger number of drugs.

Conclusions: The results show that the prevalence of IMU among community-dwelling elderly is high and depends partly on the method used to evaluate improper use. Besides the diversity of methods, other factors, such as patient sex, age and number of drugs used concurrently, appear to have influenced the estimates of IMU.

\section{Background}

The elderly are the segment of society most exposed to medication. Studies in developed countries show that consumption of medication increases with age and that many elderly use at least three prescribed drugs concurrently $[1,2]$. In developing countries, the proportion of elderly using at least one medication daily ranges from 85 to $90 \%$ [3-6]. However, physiological and physiopathological peculiarities in this age group lead to differences in the pharmacokinetics and pharmacodynamics of the medications

\footnotetext{
* Correspondence: lusiele.guaraldo@ipec.fiocruz.br

'Escola Nacional de Saúde Pública Sérgio Arouca-Fundação Oswaldo Cruz, Rio de Janeiro, Brazil

Full list of author information is available at the end of the article
}

administered, making the prescription process complex and often inappropriate $[7,8]$. Studies show that elderly patients can present alterations in practically all pharmacokinetic processes (absorption, first-pass metabolism, bioavailability, distribution, protein building, renal and hepatic clearance). These alterations can lead to lower effectiveness of some drugs, such as enalapril, which is a pro-drug, and its bioavailability can be affected by reduction of the first-step metabolism [7]. On the other hand, they can also contribute to increasing risk of adverse drug reactions; for example, drugs with high hepatic-extraction ratios, such as the nitrates, barbiturates, lidocaine and propranolol, may have reduced hepatic metabolism in older adults [9].

\section{Ciomed Central}


Today, inappropriate prescribing for the elderly is considered a major public health problem, given its association with morbidity and mortality and in view of health service costs resulting from adverse reactions $[10,11]$.

Various strategies have been developed to identify inappropriate prescription patterns. Methods are based on implicit criteria, involving clinical judgment grounded in reviews of the medical literature (Medication Appropriateness Index, for example [12]), and explicit criteria, based on consensually-generated lists of drugs to be avoided. One of the most used is the Beers method created in 1991 and updated in 1997 and 2002 [13-15].

The review by Jano \& Aparasu [10] shows that, on the Beers criteria, use of inappropriate medication is associated with adverse effects on health, especially hospitalizations, among elderly residing in the community. Concomitant use of several medications (polypharmacy) is also related to adverse reactions, morbidity and mortality [16].

Various methods have been widely used in several countries to identify inappropriate prescription patterns and their effects on the health of the elderly, and to foster improved therapeutic practice $[11,13]$. Studies show that providing information of inappropriate medication use to health authorities can help improve pharmacotherapy among the elderly by providing input to regulatory action with a view to reducing inappropriate prescribing [17].

The aims of this review are to identify and describe studies that used information from insurance company and social security administrative databases to assess inappropriate medication use among community-dwelling elderly (60 years and older) and to present the risk factors most often associated with inappropriate medication use.

\section{Methods}

\section{Search}

The paper search was conducted on the Medline electronic database, using the PubMed interface. The MeSH descriptors used were "aged" not "frail elderly" combined with "drug therapy", "drug utilization", "pharmaceutical preparations", "drug interactions" and with the free terms "inappropriate drug", "inappropriate drugs", "inappropriate medication", "inappropriate medications", "inappropriate medicines", "inappropriate prescribing”, "inappropriate prescription”, "inappropriate prescriptions", "inadequate medication", "suboptimal therapy", "suboptimal prescribing" in the paper title or abstract. The search limits were: publication date from January 1990 to June 2010, species (human), and publication type (excluding editorials, letters and reviews). The search strategy was also performed in the Embase database (the complete search strategy is presented in Additional file 1).

\section{Selection}

Papers were selected by two authors independently, and reviewed by a third author, according to the stages described below.

After reading the titles returned by the search, we excluded the following: case studies; studies in hospitals, nursing homes, or hospital emergency departments; studies of specific drugs or groups of drugs; and studies exclusively of subgroups of ill, frail elderly or rural populations. These same criteria were applied to the abstracts of the publications selected. Also excluded were guidelines and studies which offer no inappropriateness frequency estimates, as well as those without abstracts. The articles were selected with no language restriction.

On reading the abstracts it was possible, from the nature of the data, to identify two groups: studies of primary data sources and studies of secondary data sources. By reading the Methods section of each study they could be classified by the nature of the data used. This paper examines the studies of secondary data sources, i.e. insurance company and social security administrative databases developed primarily for purposes other than evaluating medication use. That choice was made in view of their representativeness and of the power to detect differences, because they contain records on large numbers of people.

The same inclusion and exclusion criteria were applied in order to select studies retrieved by manual search in the bibliographic references of the selected articles.

\section{Reading and data extraction}

Each paper was examined for: population studied, inappropriateness criterion (Beers, Drug Utilization Review; Zhan; McLeod; Medication Appropriateness Index, and others), measures of frequency of inappropriate use (proportion of elderly), description of inappropriate medications (drugs or classes of drugs), and factors associated with improper use. The exclusion criteria mentioned above were applied to the full texts.

The data extraction form and the corresponding instruction manual for completing it were tested initially with five articles and subsequently subjected to minor adjustments, such as including new data record fields or changing format to accommodate information recording better. It comprised seven sections, which can be summarized as follows: identification of the article; description of the study source data base (type; country; scope); study population (individuals/visits/prescription); characterization of the participants (age; sex; schooling; income; co-morbidity); measures of inappropriate use frequency (proportion of elderly); inappropriateness criteria used (Beers, 1991; Beers, 1997; Beers, 2002; Drug Utilization Review; Zhan; McLeod; Medication Appropriateness Index, and others); 
medications (used; inappropriate by drugs/classes of drugs); associated factors (odds ratio; confidence intervals, p-value). The form is available from the authors.

During reading of the complete texts, data quality was also evaluated for inclusion in the review. Although the Strobe Initiative [18] is not a tool for evaluating study quality, some points from it were considered here for that purpose, especially as regards the Methods section, as follows: (1) Setting: describe the setting, locations, and relevant dates, including recruitment, exposure, follow-up, and data collection periods; (2) Participants: give the eligibility criteria, and the sources and methods of selection of participants; (3) Data search: give sources of data and details of methods of assessment (measurement). These items had to be present in an article in order for it to be included in the review.

A number of terms designating inappropriate medication use were encountered: drugs to be avoided in the elderly, inappropriate drug use, potentially inappropriate medication, potentially inappropriate prescribing in the elderly, and potentially inappropriate prescribing. In this review all these terms were expressed as IMU (inappropriate medication use).

\section{Analysis}

Epidata was used for data input and analysis. A description of the studies is given as regards country and sample characteristics, inappropriateness criteria used in each article, and prevalence of IMU defined as the proportion of elderly who received at least one inappropriate medication. The factors associated with inappropriate use are also shown. Proportions were extracted to measure frequencies relating to the variables country, type of measurement of IMU used, and drugs/therapeutic classes most identified as inappropriate.

\section{Results}

The search strategy returned 628 papers (Medline and Embase); the exclusions at each stage are shown in Figure 1.

As regards the quality of the articles, we excluded one article for not defining sampling criteria and another 8 whose criteria of inappropriateness differed widely from previously validated criteria (such as Beers [13], Zhan [19] or McLeod [20]), i.e., they used criteria not specific to the elderly (2), or made extensive adaptations to drugs lists, resulting in distortion of validated criteria (4), or focused on overall quality of patient care (2).

After application of the inclusion and exclusion criteria, 19 studies were selected for analysis. In all these the population was studied retrospectively.

It was noted that, over the period reviewed (1990 to $2010)$, the number of papers published on IMU has increased steadily in more recent years, and more than doubled in the past five. Table 1 describes the main characteristics of the papers included in the review. They were produced in 5 different countries of North America, Europe, Oceania and Asia, 78.9\% (15/19) of them in the USA.

Thirty seven percent (7/19) of the studies were based on nationwide administrative databases. They all presented data on population size, expressed as numbers of individuals over 65 years old. One study (1/19) included only elderly over 70 years old, and one study (1/19) included elderly over 60 years old. Information on sex was included in $84.2 \%(16 / 19)$ of the studies. Study sample sizes ranged from 777 to 2133864 elderly.

All papers used explicit criteria of inappropriateness and $73.7 \%(14 / 19)$ used one of the three versions of Beers criteria (1991, 1997 and 2002). However, 85.7\% (12/14) adapted the criteria to restrict them to inappropriate drugs regardless of dosage or specific clinical conditions or even to drugs available in the country of the study $[21,22]$. About $16.0 \%(3 / 19)$ used more than one criterion in order to evaluate combined inappropriate medication use [23-25]. Other methods used included Zhan and HEDIS (derived from Beers criteria), which were applied in $21 \%(4 / 19)$ [26-29] and $5.3 \%(1 / 19)$ [30] of the studies, respectively.

There was clear variation in estimates of IMU prevalence. Among estimates generated by applying several criteria, prevalence of IMU ranged from $11.5 \%$ to $62.5 \%$ (Table 1).

As regards the drugs/therapeutic classes most identified as inappropriate, $36.8 \%(7 / 19)$ of the studies [22,27-29,31-33] described the inappropriate medication as individual drugs, two reported them as therapeutic classes [21,34]; nine presented rankings of classes and individual drugs [23-25,30,35-39], and one did not describe the inappropriate medications [26].

Of the studies that identified the inappropriate medications as individual drugs [22,27-29,31-33], 85.7\% (6/7) mentioned amitriptyline; $85.7 \%(6 / 7)$, propoxyphene; and $51.1 \%(4 / 7)$ cyclobenzaprine, among the five inappropriate drugs most used.

Factors associated with IMU were addressed in $68.4 \%$ $(13 / 19)$ of the studies. About $15.8 \%$ (3/19) used univariate analyses $[29,32,38]$ and $52.6 \%(10 / 19)$ multivariate analyses. The factors most often associated with IMU include: female sex, age and number of drugs prescribed or dispensed (Table 2).

\section{Discussion}

Our results suggest that prevalence of IMU is high among community-dwelling elderly, and that this use is associated with the female sex, advanced age and the number of drugs prescribed.

Studies clearly varied widely in their estimates of prevalence of inappropriate medication use by the elderly. 


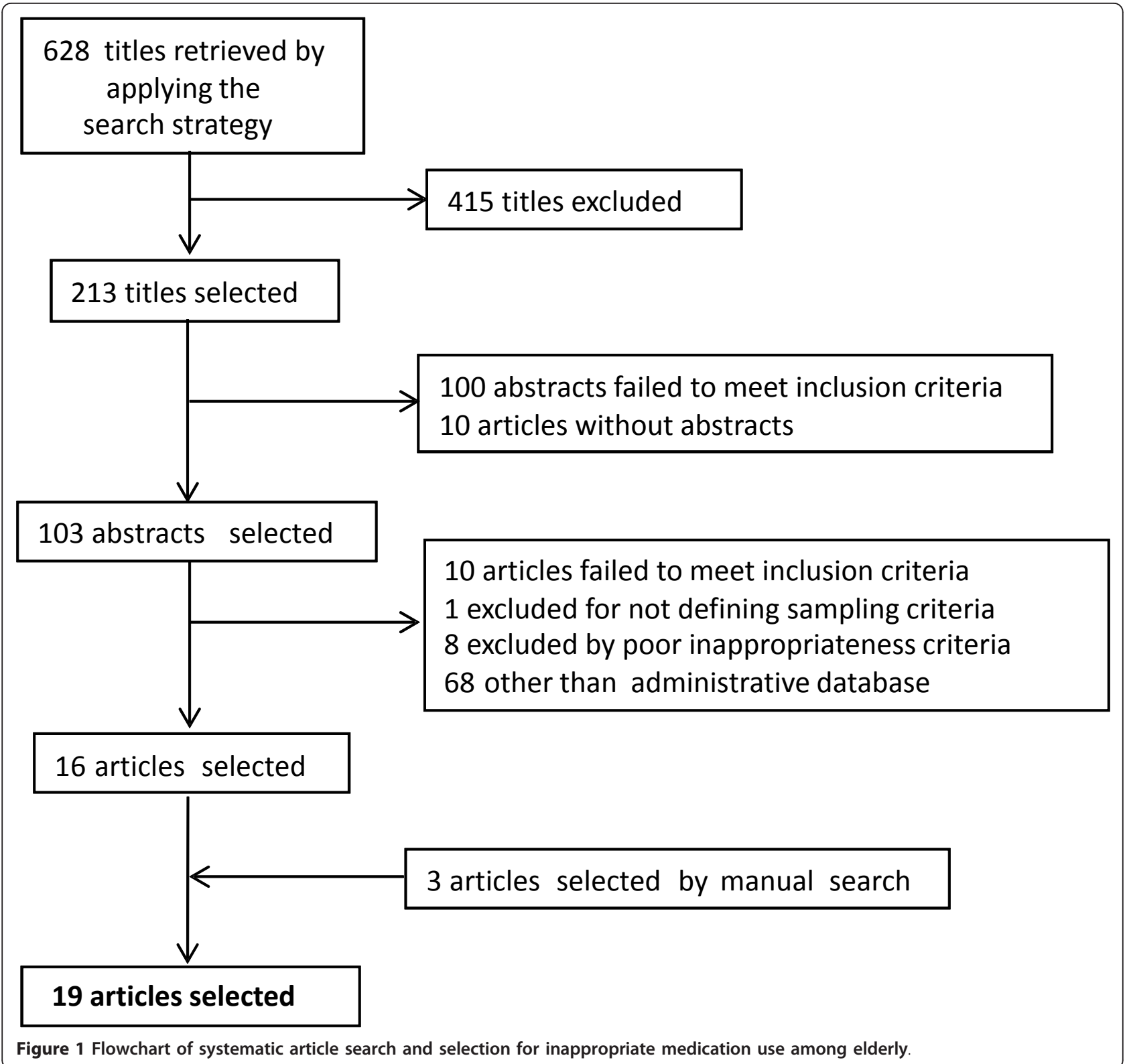

Among estimates generated by applying several criteria, prevalence of IMU ranged from $11.5 \%$ to $62.5 \%$. This variability may result from a number of factors, among them the diversity of inappropriateness criteria.

Most of the studies used classic explicit criteria, such as Beers. The Beers criteria, developed in 1991 using modified Delphi method, consists in a list of 30 drugs to be avoided in nursing home residents regardless of diagnoses, dose and frequency of medication use. Updates reflected the appearance of new drugs and knowledge, and broadened application of the criteria to ambulatory elderly [13-15]. The latest version (Beers, 2002) considers 48 inappropriate medications or classes of medications regardless of diagnosis or conditions, and inappropriate medications or classes for 20 conditions. In 2001, Zhan et al. [19] classified 1997 Beers Criteria drugs into 3 categories: "always avoid", "rarely appropriate", and "some indications". In 2003, an expert panel classified the 2003 Beers Criteria drugs into the same three categories, but only the categories "always avoid" and "rarely appropriate" were included in the HEDIS criteria [30]. The McLeod method, which is also considered explicit, was developed by a Canadian panel of experts, and consists in 18 inappropriate medications for all elderly regardless of diagnoses or conditions, 16 inappropriate drug-disease interactions, and 4 inappropriate drug-drug interactions [20]. Some studies in this review use more than one criterion [23,24] or more than one version of the same criterion simultaneously [25]. 
Table 1 Prevalence* of Inappropriate Medication Use (IMU), characteristics of studies (1990-2010)

\begin{tabular}{|c|c|c|c|c|}
\hline Reference/Year & Country/Cohort** & $\begin{array}{l}\text { Population characteristics } \\
\text { Sample(N); Sex (\% Males); } \\
\text { Age (years) }\end{array}$ & Criteria $^{\#}$ & Prevalence \\
\hline Lai et al., 2009 [21] & Taiwan/NHIRD & $\begin{array}{l}N=2133864 \text { elderly } \\
\quad \text { Age: } \geq 65\end{array}$ & $\begin{array}{c}\text { Beers } 2002 \text { (excluded drug-disease interaction, short-acting bzd, medications not } \\
\text { marketed in Taiwan, not reimbursed by NHI and classified as second-degree } \\
\text { controlled substances) }\end{array}$ & $62.5 \%$ \\
\hline Fick et al., 2008 [35] & $\begin{array}{l}\text { USA/Southeast Managed Care } \\
\text { Organization }\end{array}$ & $\begin{array}{c}N=16877 \text { elderly } \\
\text { Males:39\%**** } \\
\text { Age: } \geq 65 / \text { mean }=73.3(S D=6.47)\end{array}$ & Beers 2002 (do not use, excluded oxybutinin, dose) & $40.7 \%{ }^{\S}$ \\
\hline Pugh et al., 2008 [26] & USANA & $\begin{array}{l}\mathrm{N}=850154 \text { elderly } \\
\text { Males: } 98 \% \\
\text { Age: } \geq 65\end{array}$ & Zhan & $26.2 \%$ \\
\hline $\begin{array}{l}\text { Bierman et al., } 2007 \\
\text { [27] }\end{array}$ & USANA & $\begin{array}{l}N=965756 \text { elderly } \\
\text { Males: } 98 \% * * * \\
\text { Age: } \geq 65 \text { years }\end{array}$ & Zhan & $\begin{array}{l}23 \% \text { (men); } \\
\text { 26.7\% } \\
\text { (women) }\end{array}$ \\
\hline $\begin{array}{l}\text { Roughead et al., } 2007 \\
\text { [23] }\end{array}$ & AustraliaNA & $\begin{array}{c}N=192363 \text { elderly } \\
\text { Males: } 52.6 \% \\
\text { Age: } \geq 70 / \text { mean }=81.7(\mathrm{SD}=4.8)\end{array}$ & Beers 2002/McLeod (do not use) & $21.2 \%^{\S}$ \\
\hline $\begin{array}{l}\text { Barnett et al., } 2006 \\
\text { [28] }\end{array}$ & USANA & $\begin{array}{c}\mathrm{N}=123633 \text { elderly } \\
\text { Males:97.3\% } \\
\text { Age: } \geq 65 / \text { mean }=74.7(\mathrm{SD}=5.8)\end{array}$ & Zhan & $21.3 \% \$$ \\
\hline Maio et al., 2006 [22] & $\begin{array}{l}\text { Italy/Emilia Romagna outpatient } \\
\text { prescriptions claims database }\end{array}$ & $\begin{array}{c}N=849425 \text { elderly } \\
\text { Males: } 41.1 \% * * * \\
\text { Age: } \geq 65 / \text { mean }=75.6(S D=7.5)\end{array}$ & $\begin{array}{c}\text { Beers } 2002 \text { (do not use; excluded medications not marketed in Italy or not } \\
\text { reimbursed by the Italian National Formulary) }\end{array}$ & $18 \%$ \\
\hline Pugh et al., 2006 [30] & $\begin{array}{l}\text { USA/NPCDNA/Large Health } \\
\text { Survey of Veterans }\end{array}$ & $\begin{array}{l}N=1096361 \text { elderly } \\
\text { Males: } 98 \% * * * \\
\text { Age: } \geq 65\end{array}$ & HEDIS 2006 & $19.6 \%$ \\
\hline $\begin{array}{l}\text { Zuckerman et al., } \\
2006[34]\end{array}$ & $\begin{array}{l}\text { USA/MarketScan Medicare } \\
\text { Supplemental and Coordination } \\
\text { of Benefits }\end{array}$ & $\begin{array}{c}\mathrm{N}=487383 \text { elderly } \\
\text { Males: } 55.5 \% \\
\text { Age: } \geq 65 / \text { mean }=73.8(\mathrm{SD}=\mathrm{nr})\end{array}$ & Beers 2002 & $41.9 \%$ \\
\hline Pugh et al., 2005 [24] & USANA & 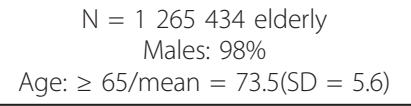 & Beers 1997 (dose)/Zhan & $23 \%$ \\
\hline Rigler et al., 2005 [36] & $\begin{array}{l}\text { USA/Kansas Medicaid } \\
\text { beneficiaries }\end{array}$ & $\begin{array}{l}N=1163 \text { elderly } \\
\text { Males: } 30.5 \% \\
\quad \text { Age: } \geq 60\end{array}$ & Beers 1997 (do not use) & $21 \%$ \\
\hline Simon et al., 2005 [29] & USA/10 HMOs & $\begin{array}{l}N=157517 \text { elderly } \\
\text { Males: } 43.5 \% \\
\text { Age: } \geq 65\end{array}$ & Zhan & $\begin{array}{l}28.8 \%(95 \% \\
\mathrm{Cl} 28.6-29.1) \\
\$ \S\end{array}$ \\
\hline Curtis et al., 2004 [37] & USA/Advanced PCS & $\begin{array}{c}N=765423 \text { elderly } \\
\text { Males: } 41.7 \% \%^{* * *} \\
\text { Age: } \geq 65 / \text { mean }=73.7(\mathrm{SD}=6.5)\end{array}$ & Beers 1997 (do not use) & $21.2 \%$ \\
\hline $\begin{array}{l}\text { Howard et al., } 2004 \\
\text { [25] }\end{array}$ & Canada/OCB/RPDB & $\begin{array}{c}N=777 \text { elderly } \\
\text { Males: } 37.5 \% \\
\text { Age: } \geq 65 / \text { mean }=74.1(S D=6.0)\end{array}$ & $\begin{array}{c}\text { Beers 1991/Beers } 1997 \begin{array}{c}\text { (included bzd with }>30 \text { days supply and }>1 \text { bzd or NSAID } \\
\text { simultaneously) }\end{array}\end{array}$ & $16.3 \%$ \\
\hline
\end{tabular}


Table 1 Prevalence* of Inappropriate Medication Use (IMU), characteristics of studies (1990-2010) (Continued)

\begin{tabular}{|c|c|c|c|c|}
\hline Rigler et al., 2004 [39] & $\begin{array}{l}\text { USA/Kansas Medicaid } \\
\text { beneficiaries }\end{array}$ & $\begin{array}{l}N=1163 \text { elderly } \\
\text { Males: } 30.5 \% \\
\text { Age: } \geq 65\end{array}$ & Beers 1997 (do not use) & $21 \%$ \\
\hline Fick et al., 2001 [33] & $\begin{array}{l}\text { USA/Southeastern } \\
\text { HMO }\end{array}$ & $\begin{array}{l}N=2336 \text { elderly } \\
\text { Males: } 40.2 \%^{* * *} \\
\text { Age: } \geq 65\end{array}$ & Beers 1997(do not use) & $24.2 \%$ \\
\hline $\begin{array}{l}\text { Mott \& Meek, } 2000 \\
\text { [38] }\end{array}$ & $\begin{array}{c}\text { USA/Database of ambulatory } \\
\text { pharmacies of a Midwestern } \\
\text { state }\end{array}$ & $\begin{array}{c}\mathrm{N}=1185 \text { elderly } \\
\text { Males:35.7\%*** } \\
\text { Age: range } 65-97 / \text { mean }=74.9(\mathrm{SD}= \\
7.06)\end{array}$ & Beers 1997 (do not use) & $14.3 \%$ \\
\hline $\begin{array}{l}\text { Piecoro et al., } 2000 \\
\text { [31] }\end{array}$ & $\begin{array}{l}\text { USA/Kentucky Medicaid } \\
\text { Recipients }\end{array}$ & $\begin{array}{c}N=44259 \text { elderly } \\
\text { Age: } \geq 65\end{array}$ & Beers 1997 (do not use, excluded antihistamines) & $24.4 \%$ \\
\hline $\begin{array}{l}\text { Futterman et al., } 1997 \\
\text { [32] }\end{array}$ & USA/HMO Medicare plan/PBM & $\begin{array}{c}N=10076 \text { elderly } \\
\text { Age: } \geq 65\end{array}$ & Beers 1991 & $\begin{array}{l}11.53 \% \\
(1994) ; 12.8 \% \\
(1993)\end{array}$ \\
\hline
\end{tabular}

${ }^{*}$ in the preceding year

** Advanced PCS = outpatient prescription claims database of national pharmaceutical benefit manager; $\mathrm{HMO}=$ Health Maintenance Organizations; $\mathrm{NHI}=\mathrm{National}$ Health Insurance program; NHIRD = National

Health Insurance Research Database - year 2004; NPCD = National Patient Care Database; OCB = Ontario Drug Benefit Plan; PBM = Pharmaceuticals benefit manager; RPDB = Registered Persons Database; VA =

Veterans Affairs administrative and pharmacy database.

*** Recovered values; $\mathrm{nr}=$ not reported

\# data in brackets refer to the subtype or modification of criteria used in the study: "do not use" refers to drugs that should be avoided in any circumstances, "dose" refers to drug doses that should not be exceeded

and "drug-disease interactions" refers to drugs to avoid in patients with specific conditions; bzd = benzodiazepines; HEDIS = Healthcare Effectiveness Data and Information measures.

${ }^{\S}$ prevalence in the preceding 6 months; ${ }^{\S \S}$ prevalence in the preceding 18 months 
in the elderly are present in several explicit methods and associated with severe adverse events, such as sedation, falls and cognitive dysfunctions [13,41]. However, it is important to consider that only the short-acting benzodiazepines were strongly associated with fall-related injuries and that nowadays, the tricyclic antidepressants have been largely replaced by selective serotonin reuptake inhibitors because of lesser adverse effects [41]. Prescription of medication to treat these diseases thus deserves close attention, given that withdrawal of such medication is associated with a reduction in adverse effects, and improvements in physical and cognitive functions in the elderly [42].

This review was intended to contribute to knowledge about pharmacotherapy for the elderly by evaluating a non-institutionalized population. Our search strategy identified a large body of literature. Nonetheless, we may have missed relevant articles that were not identified, unpublished or excluded erroneously. Reliable evaluation of the vast and heterogeneous bibliographical material was assured by independent duplicate reading, and review by a third author at all stages of data selection and extraction. Certain limitations must be considered, however. Firstly, this review addressed only studies of administrative data sources, which are retrospective and have gaps in clinical information and in drug exposure data. On the other hand, they offer information on large populations. The number of articles published has been growing over the past few years. Contributions to the conceptual framework [43] and statistical approaches [44] have allowed a better understanding of the large administrative database as a valid means to examine the quality of medical services. Here, they were chosen for their representativeness, which yields more precise estimates and power to detect differences that otherwise would not offer statistical significance. As observed in Table 2 the confidence intervals of estimates for the association between inappropriate medication use and sex, age or number of medications are very small. Studies of administrative data sources may also be useful as inexpensive screening tools in areas where quality can be investigated in greater depth. Lastly, this review did not address the repercussions of inappropriate medication use on the health of the elderly nor the capacity of the methods used to predict adverse outcomes, both of which are important considerations for clinical practice.

As more studies are published, it may be possible to measure and record all potentially important covariates. These should be considered in future studies in order to improve the ability to identify their impact on the estimates and develop control strategies. Variables such as sex, age and total number of medications used should be mandatory in future studies. It is also important to give attention to other sources of information, such as medical records and surveys, with a view to ascertaining to what extent different study designs entail discrepant results. Moreover, in the future, reviews of articles that analyze primary data from population surveys - with information on social variables, demographics, health status, diseases, lifestyle habits, and physical and mental limitations - can enrich our understanding of the complex network of factors involved in prescribing drugs for the elderly.

\section{Conclusions}

Inappropriate medication use is a public health problem and must be evaluated constantly as the panorama of pharmacotherapy changes. However, estimates of IMU can be influenced by diverse factors relating to the detection method used and the study population.

Identifying vulnerable patient groups and developing pharmacological alternatives suited to country-specific conditions are important strategies for orienting clinical conduct and risk reduction in this age group.

From reading the articles, the authors identified certain salient problem areas, which could be worked around in the future. Prominent among them is the applicability of the list of drugs. There is a need for scientific evidencebased lists to be drawn up with clearly defined indicators of inappropriate medication prescription, as well as drugdrug and drug-disease interactions [45]. This recommendation is even more important in the case of large administrative data bases. This would then provide an easily applicable tool with major potential for research and monitoring, to be used by researchers and health system managers. Another still unsolved problem relates to the existence of lists compiled by only a few countries. It is important to develop lists appropriate to the products on sale in each country, so as to make it easier to operationalize studies, and for surveillance systems to monitor. In addition, the inclusion of lists of medications inappropriate for the elderly on national drug formularies would reduce their prescription and use in this age group [46]. However, the development of more suitable criteria of inappropriateness does not itself guarantee reduced prevalence of IMU. Efforts to identify factors associated with IMU may help policy makers identify vulnerable patient groups and develop programs to modify prescription patterns $[47,48]$. Studies of large administrative data bases, such as those analyzed in this study, can make a major contribution in this respect. However, it is essential to develop effective approaches. Geriatric medicine services, pharmacist interventions in patient care, implementation of appropriate prescription criteria and computerized decision-making support systems can improve the appropriateness of prescribing for the elderly in ambulatorycare settings [49-52]. The review by Forsetlund et al [53] shows that, in nursing homes, under certain circumstances, interventions using educational outreach, on-site 
education alone or as part of an intervention package and pharmacists medication review may reduce inappropriate medication drug use.

\section{Additional material}

Additional file 1: Search Strategy. the file presents the complete search strategy performed in Medline and Embase databases.

\section{Author details}

${ }^{1}$ Escola Nacional de Saúde Pública Sérgio Arouca-Fundação Oswaldo Cruz, Rio de Janeiro, Brazil. ${ }^{2}$ Instituto de Pesquisa Clínica Evandro ChagasFundação Oswaldo Cruz, Rio de Janeiro, Brazil. ${ }^{3}$ Universidade Estadual do Oeste do Paraná, Cascavel, Brazil.

\section{Authors' contributions}

LG, FGC and SR were involved in the conceptualization of the research question. LG, FGC, GSD and SR devised the search strategy, and identified and appraised relevant literature. SR acted as third reviewer, assisting in appraisal and interpretation of relevant studies where agreement could not be met. LG drafted the manuscript with critical input from all other authors. All authors read and approved the final manuscript.

\section{Competing interests}

The authors declare that they have no competing interests.

Received: 17 March 2011 Accepted: 30 November 2011

Published: 30 November 2011

\section{References}

1. Barat I, Andreasen F, Damsgaard EMS: The consumption of drugs by 75year-old individuals living in their own homes. Eur J Clin Pharmacol 2000, 56(6-7):501-9.

2. Kaufman DW, Kelly JP, Rosenberg L, Anderson TE, Mitchell AA: Recent patterns of medication use in the ambulatory adult population of the United States: the Slone survey. JAMA 2002, 287(3):337-44.

3. Mosegui GB, Rozenfeld S, Veras RP, Vianna CM: Quality assessment of drug use in the elderly. Rev Saúde Pública 1999, 33(5):437-44.

4. Bertoldi AD, Barros AJD, Hallal PC, Lima RC: Drug utilization in adults: prevalence and individuals determinants. Rev Saúde Pública 2004, 38(2):228-38.

5. Ribeiro AQ, Rozenfeld S, Klein $\mathrm{CH}$, César CC, Acurcio FA: Survey on medicine use by elderly retirees in Belo Horizonte, Southeastern Brazil. Rev Saúde Pública 2008, 42(4):724-32.

6. Rozenfeld S, Fonseca MJ, Acurcio FA: Drug utilization and polypharmacy among the elderly: a survey in Rio de Janeiro City, Brazil. Rev Panam Salud Publica 2008, 23(1):34-43.

7. Mangoni AA, Jackson HD: Age-related changes in pharmacokinetics and pharmacodynamics: basic principles and practical applications. Br J Clin Pharmacol 2004, 57(1):6-14.

8. McLean AJ, Le Couteur DG: Aging Biology and Geriatric Clinical Pharmacology. Pharmacol Rev 2004, 56(2):163-84.

9. Kim J, Cooper A: Geriatric Therapy. In Applied Therapeutics: the clinical use of drugs.. 8 edition. Edited by: Koda-Kimble MA, Young LY, Kradjian WA, Guglielmo BJ. Philadelphia: Lippicott Williams 2005:1-19.

10. Jano E, Aparasu RR: Healthcare Outcomes Associated with Beers' Criteria: A Systematic Review. Ann Pharmacoth 2007, 41(3):438-47.

11. Spinewine A, Schmader KE, Barber N, Hughes C, Lapane KL, Swine C, Hanlon JT: Appropriate prescribing in elderly people: how well can it be measured and optimized? Lancet 2007, 370(9582):173-84.

12. Hanlon JT, Schmader KE, Samsa GP, Weinberger M, Uttech KM, Lewis IK, Cohen HJ, Feussner JR: A method for assessing drug therapy appropriateness. J Clin Epidemiol 1992, 45(10):1045-51.

13. Fick DM, Cooper JW, Wade WE, Waller JL, Maclean JR, Beers MH: Updating the Beers Criteria for Potentially Inappropriate Medication Use in Older
Adults: results of a US consensus panel of experts. Arch Intern Med 2003, 163(22):2716-24.

14. Beers MH, Ouslander JG, Rolingher J, Reuben DB, Brooks J, Beck JC: Explicit criteria for determining inappropriate medication use in nursing home residents. UCLA Division of Geriatric Medicine. Arch Intern Med 1991, 151(9):1825-32.

15. Beers $\mathrm{MH}$ : Explicit criteria for determining potentially inappropriate medication use by the elderly. Arch Intern Med 1997, 157(14):1531-6.

16. Hajjar EM, Cafiero AC, Hanlon JT: Polypharmacy in Elderly Patients. Am J Geriatr Pharmacother 2007, 5(4):345-51.

17. Kaur S, Mitchell G, Vitetta L, Roberts MS: Interventions that can Reduce Inappropriate Prescribing in the Elderly. A Systematic Review. Drugs Aging 2009, 26(12):1013-28.

18. von Elm E, Altman DG, Egger M, Pocock SJ, Gøtzsche PC, Vandenbroucke JP: STROBE Initiative. Strengthening the Reporting of Observational Studies in Epidemiology (STROBE) statement: guidelines for reporting observational studies. BMJ 2007, 335(7624):806-8.

19. Zhan C, Sangl J, Bierman AS, Miller MR, Friedman B, Wickizer SW, Meyer GS: Potentially inappropriate medication use in the community-dwelling elderly: findings from the 1996 Medical Expenditure Panel Survey. JAMA 2001, 286(22):2823-9.

20. McLeod PJ, Huang AR, Tamblyn RM, Gayton DC: Defining inappropriate practices in prescribing for elderly people: a national consensus panel. CMAJ 1997, 156(3):385-91.

21. Lai HY, Hwang SJ, Chen YC, Chen TJ, Lin MH, Chen LK: Prevalence of the prescribing of potentially inappropriate medications at ambulatory care visits by elderly patients covered by the Taiwanese National Health Insurance program. Clin Ther 2009, 31(8):1859-70.

22. Maio V, Yuen EJ, Novielli K, Smith KD, Louis DZ: Potentially inappropriate medication prescribing for elderly outpatients in Emilia Romagna, Italy: a population-based cohort study. Drugs Aging 2006, 23(11):915-24.

23. Roughead EE, Anderson B, Gilbert AL: Potentially inappropriate prescribing among Australian veterans and war widows/widowers. Intern Med J 2007, 37(6):402-5.

24. Pugh MJ, Fincke BG, Bierman AS, Chang BH, Rosen AK, Cunningham FE, Amuan ME, Burk ML, Berlowitz DR: Potentially inappropriate prescribing in elderly veterans: are we using the wrong drug, wrong dose, or wrong duration? J Am Geriatr Soc 2005, 53(8):1282-9.

25. Howard M, Dolovich L, Kaczorowski J, Sellors C, Sellors J: Prescribing of potentially inappropriate medications to elderly people. Fam Pract 2004, 21(3):244-7.

26. Pugh MJ, Rosen AK, Montez-Rath M, Amuan ME, Fincke BG, Burk M, Bierman A, Cunningham F, Mortensen EM, Berlowitz DR: Potentially inappropriate prescribing for the elderly: effects of geriatric care at the patient and health care system level. Med Care 2008, 46(2):167-73.

27. Bierman AS, Pugh MJ, Dhalla I, Amuan M, Fincke BG, Rosen A, Berlowitz DR: Sex differences in inappropriate prescribing among elderly veterans. Am J Geriatr Pharmacother 2007, 5(2):147-61.

28. Barnett MJ, Perry PJ, Langstaff JD, Kaboli PJ: Comparison of rates of potentially inappropriate medication use according to the Zhan criteria for VA versus private sector Medicare HMOs. J Manag Care Pharm 2006, 12(5):362-70.

29. Simon SR, Chan KA, Soumerai SB, Wagner AK, Andrade SE, Feldstein AC, Lafata JE, Davis RL, Gurwitz JH: Potentially inappropriate medication use by elderly persons in U.S. Health Maintenance Organizations, 2000-2001. J Am Geriatr Soc 2005, 53(2):227-32.

30. Pugh MJ, Hanlon JT, Zeber JE, Bierman A, Cornell J, Berlowitz DR: Assessing potentially inappropriate prescribing in the elderly Veterans Affairs population using the HEDIS 2006 quality measure. J Manag Care Pharm 2006, 12(7):537-45.

31. Piecoro LT, Browning SR, Prince TS, Ranz TT, Scutchfield FD: A database analysis of potentially inappropriate drug use in an elderly Medicaid population. Pharmacotherapy 2000, 20(2):221-8.

32. Futterman R, Fillit $H$, Roglieri JL: Use of ineffective or unsafe medications among members of a Medicare HMO compared to individuals in a Medicare fee-for-service program. Am J Manag Care 1997, 3(4):569-75.

33. Fick DM, Waller JL, Maclean JR, Heuvel RV, Tadlock JG, Gottlieb M, Cangialose CB: Potentially Inappropriate Medication Use in a Medicare Managed Care Population: Association with Higher Costs and Utilization. J Managed Care Pharm 2001, 7(5):407-13. 
34. Zuckerman $H$, Langenberg P, Baumgarten M, Orwig D, Byrns PJ, SimoniWastila L, Magaziner J: Inappropriate Drug Use and Risk of Transition to Nursing Homes Among Community-Dwelling Older Adults. Med Care 2006, 44(8):722-30.

35. Fick DM, Mion LC, Beers MH, L Waller J: Health outcomes associated with potentially inappropriate medication use in older adults. Res Nurs Health 2008, 31(1):42-51.

36. Rigler SK, Jachna CM, Perera S, Shireman TI, Eng ML: Patterns of potentially inappropriate medication use across three cohorts of older Medicaid recipients. Ann Pharmacother 2005, 39(7-8):1175-81.

37. Curtis LH, Østbye $T$, Sendersky V, Hutchison S, Dans PE, Wright A, Woosley RL, Schulman KA: Inappropriate prescribing for elderly Americans in a large outpatient population. Arch Intern Med 2004, 164(15):1621-5.

38. Mott DA, Meek PD: Evaluating prescriptions for the elderly: drug/age criteria as a tool to help community pharmacists. J Am Pharm Assoc (Wash) 2000, 40(3):417-24.

39. Rigler SK, Perera S, Jachna C, Shireman TI, Eng M: Comparison of the Association Between Disease Burden and Inappropriate Medication Use Across Three Cohorts of Older Adults. Am J Geriatr Pharmacother 2004, 2(4):239-47.

40. World Health Organization: The World Health Report 2001: Mental health: new understanding, new hope. Geneva: WHO; 2001.

41. Chang CB, Chan DC: Comparison of published explicit criteria for potentially inappropriate medications in older adults. Drugs Aging 2010, 27(12):947-57.

42. Iyer S, Naganathan V, McLachlan AJ, Le Couteur DG: Medication Withdrawal Trials in People Aged 65 Years and Older. A Systematic Review. Drugs Aging 2008, 25(12):1021-31.

43. Wray NP, Ashton CM, Kuykendall DH, Hollingsworth JC: Using administrative databases to evaluate the quality of medical care: a conceptual framework. Soc Sci Med 1995, 40(12):1707-1715.

44. Nebeker JR, Yarnold PR, Soltysik RC, Sauer BC, Sims SA, Samore MH, Rupper RW, Swanson KM, Savitz LA, Shinogle J, Xu W: Developing indicators of inpatient adverse drug events through nonlinear analysis using administrative data. Medical Care 2007, 45(10 Supl 2):S81-S88.

45. Gallagher $P$, Barry $P, O^{\prime}$ Mahony D: Inappropriate prescribing in the elderly. J Clin Pharm Ther 2007, 32(2):113-21.

46. Zhan C: Inappropriate medication use in the elderly. Journal of the Pharmacy Society of Wisconsin 2005, May-June:29-33.

47. Aparasu RR, Mort JR: Inappropriate prescribing for the elderly: Beers criteria-based review. Ann Pharmacother 2000, 34(3):338-46.

48. Liu GG, Christensen DB: The continuing challenge of inappropriate prescribing in the elderly: an update of the evidence. $J$ Am Pharm Assoc (Wash) 2002, 42(6):847-57.

49. Hanlon JT, Weinberger M, Samsa GP, Schmader KE, Uttech KM, Lewis IK, Cowper PA, Landsman PB, Cohen HJ, Feussner JR: A randomized, controlled trial of a clinical pharmacist intervention to improve inappropriate prescribing in elderly outpatients with polypharmacy. Am J Med 1996, 100(4):428-37.

50. Tamblyn R, Huang A, Perreault R, Jacques A, Roy D, Hanley J, McLeod P, Laprise R: The medical office of the $21^{\text {st }}$ century (MOXXI): effectiveness of computerized decision-making support in reducing inappropriate prescribing in primary care. CMAJ 2003, 169(6):549-56.

51. Strandberg TE, Pitkala KH, Berglind S, Nieminen MS, Tilvis RS: Multifactorial intervention to prevent recurrent cardiovascular events in patients 75 years or older: the Drugs and Evidence-Based Medicine in the Elderly (DEBATE) study: a randomized, controlled trial. Am Heart J 2006, 152(3):585-92.

52. Gallagher PF, O'Connor MN, O'Mahony D: Prevention of potentially inappropriate prescribing for elderly patients: a randomized controlled trial using STOPP/START criteria. Clin Pharmacol Ther 2011, 89(6):845-54.

53. Forsetlund L, Eike MC, Gjerberg E, Vist GE: Effect of interventions to reduce potentially inappropriate use of drugs in nursing homes: a systematic review of randomised controlled trials. BMC Geriatr 2011 $11: 16$.

\section{Pre-publication history}

The pre-publication history for this paper can be accessed here:

http://www.biomedcentral.com/1471-2318/11/79/prepub doi:10.1186/1471-2318-11-79

Cite this article as: Guaraldo et al:: Inappropriate medication use among the elderly: a systematic review of administrative databases. BMC Geriatrics 2011 11:79.

\section{Submit your next manuscript to BioMed Central and take full advantage of:}

- Convenient online submission

- Thorough peer review

- No space constraints or color figure charges

- Immediate publication on acceptance

- Inclusion in PubMed, CAS, Scopus and Google Scholar

- Research which is freely available for redistribution

Submit your manuscript at www.biomedcentral.com/submit
C Biomed Central 